\title{
Policy Level Improvement in Hydropower Development
}

\author{
Bikash Thapa
}

\begin{abstract}
Mother Nature has given Nepal a vast opportunity for hydro energy production, but still the country is reeling under painful load shedding due to an electric power production deficit of $70 \mathrm{MW}$. The main challenge for the country now is to harness the hydropower potentiality, which contributes for its economic development. In Nepal, policy deficiencies and the slow decision making process in electricity sector has resulted in the increased project costs and has reduced the involvement of private sectors and the entrepreneurs. Thus, restructuring and improvements at all policy level is required to overcome various hurdles, and then only will hydropower develop in Nepal.
\end{abstract}

Nepal is reeling under painful load shedding due to an electric power production deficit of 70 MW. Due to the political unrest the state is unable to give due attention to its production.

Once the ongoing political instability is settled, economic development will be the national agenda. As hydropower is the backbone of economic development, policy level improvements need to be strengthened by reviewing the progress made so far and learning from past shortfalls.

Hydropower developed during the democratic period only after the year 1988. After the People's Movement, Jana Aandolan-I, that year, the installed capacity reached $614 \mathrm{MW}$, whereas it was only 300 MW in the previous 30-year Panchayat era. The private sector played an important role in its development. Failure to meet the normal demand for energy will continue; however, even after completion of any new 30oMW capacity project. The Nepal Electricity Authority (NEA) has not supplemented a single kW during the last five years. The 70 MW Middle Marshyangdi Hydroelectric Project is not likely to be completed in five years although it was planned to be completed within three years. The main reason for the delay is the political insecurity that is compounded with wrong policies of NEA and the government.

Without electricity, new factories, industries and daily activities like business expansion is not possible. Revenue to the state is generated from industrial production which requires electric energy. Mother Nature has given Nepal a vast opportunity for energy production that is not available in most countries of the world. The generation of hydropower is environmentally friendly and the resources required are abundantly available in Nepal. The main challenge is how to harness this vast potentiality.

The 10th Five Year Plan had a target to generate 314 MW hydroelectric energy, out of which 214 MW was to be generated from the private sector and the rest by government agencies. At the end of the 10th Plan, however, the capacity generated was only $40 \mathrm{MW}$, to which the contribution of the government was almost nil. The main reason behind absence of the private sector in its development is due to policy deficiencies. The Finance Act nullified the facilities granted by the Hydropower Development Policy to attract the private sector. For example, there was no corporate income tax for 15 years and no tax up to $1000 \mathrm{~kW}$. The facility of $1 \%$ custom duty and no VAT were cancelled by Finance Act. The policy envisioned that the hydropower generated would be cheap. Hydropower and vegetable industries were placed in one category which made investors reluctant to invest. Thus, the wrong message was delivered due to the change in policy. The one window policy to facilitate hydropower development is not working. A letter from the Department of Electricity Development (DOED) is not even considered by a clerk of the Custom Office.

Decision making processes in Nepal are very slow and lethargic in the electricity sector. This has resulted in increasing project costs and has halted the entry of additional entrepreneurs. Therefore, restructuring at all policy levels is required.

Policies need to benefit consumers and investments must be competitive. Institutional restructuring is essential to develop hydropower as a national industry. Policies concerning customs and tax, as well as on forest cover have to be reviewed, as the Ministry of Forest and Soil Conservation has propagated a policy to require forest cover area as $45 \%$ when most of the transmission lines and power houses are located in forest areas. The harassment and pain in obtaining forest land for lease has discouraged entrepreneurs. 
It is not only the policies of the Government that have harassed the private developers, but also NEA's undeclared policies. The Power Purchase Agreement (PPA) is an instrument that determines the return on hydropower investment. But, as the NEA has not paid much attention to the PPA over the last three years, developers with licenses cannot move ahead.

The DOED has issued 174 licenses for about $3000 \mathrm{MW}$, and are 64 projects below one megawatt. Out of these, some may have problems; but the main constraint is the lack of attention to the PPA. Mr. Anup Kumar Upadhyay, the Joint Secretary for the Ministry of Water Resources, has stated that the desired level of hydropower development is only possible through the investments of both the public as well as the private sectors. It is imperative to create a conducive environment to the private sector for domestic consumption. He holds the view that prior information on power purchase and pricing policy, where PPA can be done, must be given appropriately in order to attract private sector investment.

The ex-Director General of the DOED, Mr. Jayakeshar Maike, is of the opinion that in the absence of the PPA, projects have not developed. The NEA is avoiding the PPA with the excuse that there is a lack of transmission lines. After the Arun-III project, the NEA has concentrated only in generation projects. He says that today's results are due to negligence in the construction of new transmission lines. In Mr. Maike's opinion, it is of utmost necessity to make policy level improvements. In the public sector, delays in decision making are hampering progress, thereby increasing the cost. Further, he adds that production, transmission and distribution of the NEA must be unbundled. Only then will competition be properly induced in all sectors.

In the absence of an adequate investment environment in Nepal, young entrepreneurs like Mr. Sujit Acharya are constructing projects over four megawatts in north India's Himanchal Pradesh state. He is of the opinion that there should be a difference in policy for small and big projects. Fourteen proposals have been submitted for projects like the Upper Karnali, Arun-III and Budhi Gandaki. This will fulfill some of the energy needs of India. "We can earn billions by selling licenses to Indian Companies", says Mr. Acharya. "The policy for increasing tariff shall be made first while issuing licenses".

The NEA has different versions for making leaps in hydro-development. Mr. Bhoj Raj Regmi, General Manager for Engineering in the NEA is of the opinion that models should be different for small, medium and big projects, while keeping the already invested projects open. "Project size and investment models should be mixed", he says. Development will be fast, he maintains, if there is diversification in investment and project selection.

Mr. Ramakant Gauro, Engineer and Member of the Nepal Planning Commission, is of the opinion that policy should exist to make all the possible projects exploitable for national electrification and that the surplus to be sold to India. According to him while talking on exporting the electricity to India, many people asserted that the country's hydropower production is being sold out. He further says: "Let us hope that we will not be blamed for selling the country while exporting electricity to our neighbor."

To conclude, policy level improvements are required to overcome various constraints and hurdles. Only then will hydropower develop in Nepal.

Bikash Thapa, holds a masters degree in Business Administration. At present, he is Senior Reporter/Sub-Editor for Kantipur Publications Pvt. Ltd. His reporting sector includes Water Resources i.e. hydropower, energy, irrigation, drinking water and inundation.

Corresponding address: bikash@kantipur.com.np ort_bikash@hotmail.com 